University of Louisville

ThinkIR: The University of Louisville's Institutional Repository

Electronic Theses and Dissertations

8-2014

\title{
Nanofluid enhancement of mineral oil and thermal properties instrument design.
}

Eli Wilborn

University of Louisville

Follow this and additional works at: https://ir.library.louisville.edu/etd

\section{Recommended Citation}

Wilborn, Eli, "Nanofluid enhancement of mineral oil and thermal properties instrument design." (2014). Electronic Theses and Dissertations. Paper 1568.

https://doi.org/10.18297/etd/1568

This Master's Thesis is brought to you for free and open access by ThinkIR: The University of Louisville's Institutional Repository. It has been accepted for inclusion in Electronic Theses and Dissertations by an authorized administrator of ThinkIR: The University of Louisville's Institutional Repository. This title appears here courtesy of the author, who has retained all other copyrights. For more information, please contact thinkir@louisville.edu. 


\title{
NANOFLUID ENHANCEMENT OF MINERAL OIL AND THERMAL PROPERTIES
} INSTRUMENT DESIGN

\section{By}

\section{Eli Wilborn}

B.S., University of Louisville, 2013

\author{
A Thesis \\ Submitted to the Faculty of the \\ University of Louisville
}

J. B. Speed School of Engineering

As Partial Fulfillment of the Requirements

For the Professional Degree

\section{MASTER OF ENGINEERING}

Department of Chemical Engineering

August 2014 



\title{
NANOFLUID ENHANCEMENT OF MINERAL OIL AND THERMAL PROPERTIES
} INSTRUMENT DESIGN

\author{
Submitted by:
}

Eli Wilborn

A Thesis Approved On

(Date)

by the Following Reading and Examination Committee:

Gerold Willing, Thesis Director

James Watters

Angela Thompson 


\section{ACKNOWLEDGEMENTS}

I would like to thank my thesis advisor, Dr. Willing, for the continued direction and support for the entirety of my thesis. He has been very instrumental in the direction of this project and I am very grateful for his help.

I would like to thank Dr. Watters and Dr. Thompson for taking the time to sit on my thesis committee.

I would also like to thank my family and friends for their support. 


\begin{abstract}
There are two purposes of this research, to design and build a heat transfer cell that could accurately calculate heat transport coefficients of various fluids and to determine if the increased heat transfer capabilities of nanofluids can be applied to cooling transformers by using the heat transfer cell to measure the enhancement. The design and construction of a heat transfer cell that could accurately calculate heat transport coefficients of various fluids was successful. A heat transfer cell was built and tested on several fluids to confirm the accuracy of the design and the experiments. Three fluids were successfully tested overall for their thermal conductivity values, and one fluid was tested for its convection coefficients in the heat transfer cells. Values for the thermal conductivity and the convection coefficients were obtained during this experiment that agreed with commonly accepted values for the testing fluids. The average value for the thermal conductivities for mineral oil of the first design in the $1 / 4$ " diameter cell is $0.15 \frac{W}{m^{2} C}$, and agrees well with the commonly accepted values of mineral oils. The value commonly accepted value of thermal conductivity for mineral oil is $0.14 \frac{\mathrm{W}}{\mathrm{m}^{2} \mathrm{C}}$ at $25^{\circ} \mathrm{C}$, the first heat transfer cell yielded a thermal conductivity value of approximately $0.16 \frac{\mathrm{W}}{\mathrm{m}^{2} \mathrm{C}}$ at roughly $25 \mathrm{C}$. The heat transfer cell was also used to calculated convection coefficients of mineral oil, and values were obtained within the limits for natural convection according to Incropera, contributing more to the validity of the results from this heat transfer cell.
\end{abstract}


A second heat transfer cell was designed to determine the thermal conductivities of more thermally sensitive fluids, offering a wider range of materials that can be tested. The second design places the thermocouples directly at their assumed position of the wire and the wall temperatures for calculation purposes, yielding more accurate results and can therefore more accurately calculate the thermal conductivities of various fluids. The second design calculated a thermal conductivity of water to be $0.59 \frac{\mathrm{W}}{\mathrm{m}^{2} \mathrm{C}}$, while the commonly accepted value is $0.58 \frac{\mathrm{W}}{\mathrm{m}^{2} \mathrm{C}}$, which is well within a tolerable range of error to accept this value as accurate at the experimental conditions. This heat transfer cell also calculated the thermal conductivity value for AMSOIL synthetic motor oil to be $0.12 \frac{\mathrm{W}}{\mathrm{m}^{2} \mathrm{C}}$ and $0.10 \frac{W}{m^{2} C}$ for mineral oil, both of these values are within the expected ranges of thermal conductivity for oils.

The second goal of applying the heat transfer enhancement properties of a nanofluid to a transformer cooling application proved to be futile for Copper Oxide(40nm) and Carbon coated Copper nanoparticles $(25 \mathrm{~nm})$ in mineral oil. All of the attempted nanofluids fell out of suspension within a timeframe of a day, and in a transformer cell where natural convection is the only means of flow available that contributes to keeping the nanoparticles suspended, there is not enough flow to keep the nanoparticles from falling out of suspension. That is why unless the transformer industry moves towards another coolant besides mineral oil, heat transfer enhancement using Copper Oxide (40nm) or Carbon Coated nanoparticles $(25 \mathrm{~nm})$ in a mineral oil nanofluid is not a viable option. 
TABLE OF CONTENTS

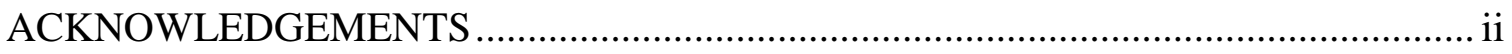

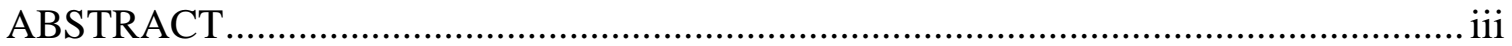

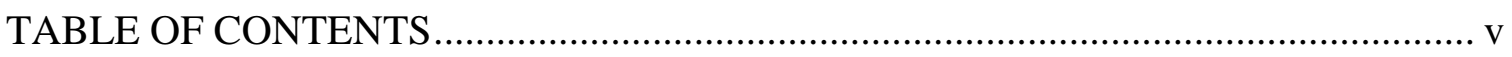

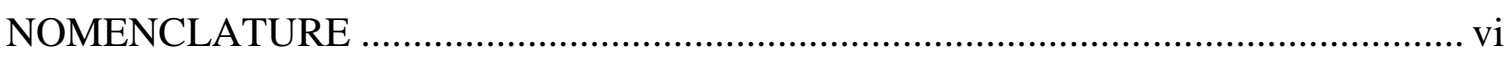

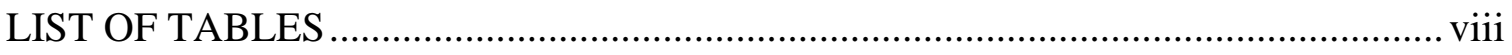

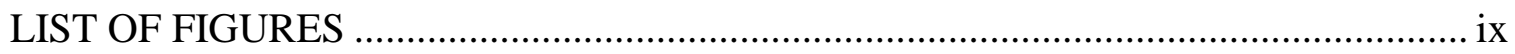

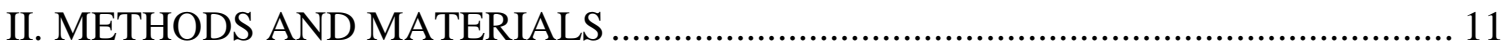

A. Procedures For Nanofluid Preparation.................................................................... 18

B. Procedure for Experimental Heat Transfer Cell Operation........................................ 19

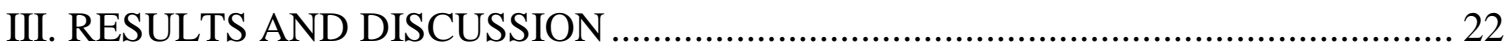

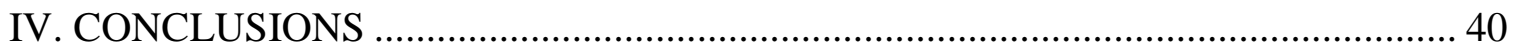

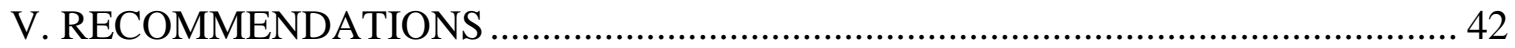

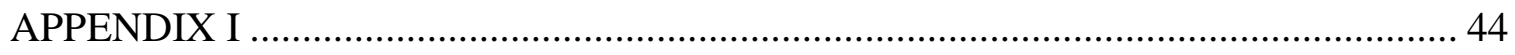

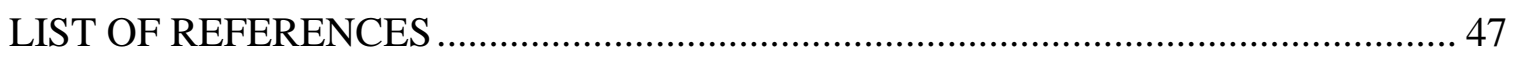

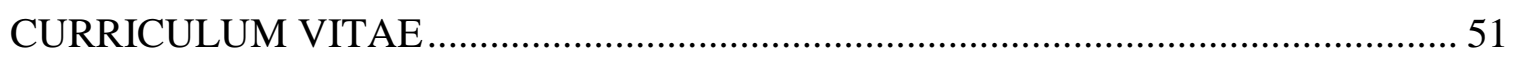




\section{NOMENCLATURE}

\begin{tabular}{|c|c|c|}
\hline$A$ & $=$ & Surface area for heat transfer \\
\hline$A A$ & $=$ & Correlation for heat capacity calculation \\
\hline$B$ & $=$ & Correlation for heat capacity calculation \\
\hline C & $=$ & Representation of Euler's constant, $\ln (C)=0.5772$ \\
\hline$D$ & $=$ & Diameter \\
\hline I & $=$ & Amperage \\
\hline$L$ & $=$ & Length \\
\hline$Q / q$ & $=$ & Heat being transported \\
\hline$T$ & $=$ & Temperature \\
\hline V & $=$ & Voltage \\
\hline$h$ & $=$ & Convection coefficient \\
\hline K & $=$ & Thermal conductivity \\
\hline$r$ & $=$ & Radius of the pipe \\
\hline$t$ & $=$ & Time to reach equilibrium \\
\hline$x$ & $=$ & Distance the heat travels \\
\hline$\Delta T$ & $=$ & Difference in temperature between the heat source and the heat sink \\
\hline$\propto$ & $=$ & Thermal Diffusivity \\
\hline$C_{p}$ & $=$ & Heat capacity of the fluid being tested \\
\hline$c_{p, f}$ & $=$ & Heat capacity of the base fluid \\
\hline$c_{p, n p}$ & $=$ & Heat capacity of the nanoparticle \\
\hline
\end{tabular}




$\begin{array}{lll}c_{p, n f} & = & \text { Heat capacity of the nanoparticle enhanced fluid } \\ \rho & = & \text { Density } \\ \rho_{f} & = & \text { Density of the base fluid } \\ \rho_{n p} & = & \text { Density of the nanoparticle } \\ \varphi & = & \text { Volume fraction of the nanoparticle }\end{array}$




\section{LIST OF TABLES}

TABLE I-VALUES FOR SUPPLIED Q AND STEPS FOR EXPERIMENTS .................. 21

TABLE II-DATA FOR MINERAL OIL IN FIRST HEAT TRANSFER CELL............... 29

TABLE III-GENERAL THERMAL CONDUCTIVITY VALUES FOR MINERAL OIL

AND AMSOIL AND REPORTED VALUE FOR DI WATER ............................... 37

TABLE IV-RESULTS FROM THE FIRST AND SECOND HEAT TRANSFER CELLS 38

TABLE V- HEAT TRANSFER RESULTS FROM NANOFLUID EXPERIMENTS ....... 45

TABLE VI-RESULTS FROM THE REPEATED 1/4" HEAT TRANSFER CELL OF THE

FIRST DESIGN WITH FRESH MINERAL OIL ............................................ 46 


\section{LIST OF FIGURES}

FIGURE 1-ILLUSTRATION OF FIRST EXPERIMENTAL HEAT TRANSFER CELL12 FIGURE 2-ILLUSTRATION OF SECOND EXPERIMENTAL HEAT TRANSFER

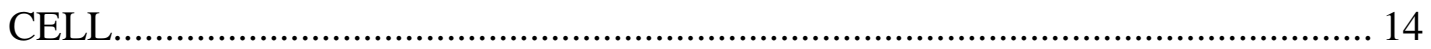

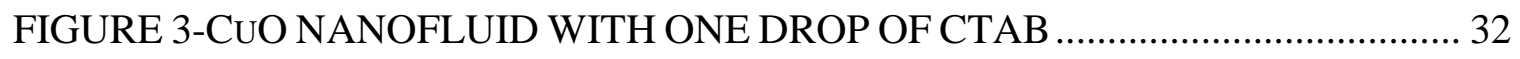

FIGURE 4-CUO NANOFLUID WITH 1 DROP CTAB, 1\% WT ................................. 33

FIGURE 5-CUO NANOFLUID WITH 2 AND 3 DROPS CTAB, 1\% WT .................... 34

FIGURE 6-CARBON COATED COPPER NANOFLUID ....................................... 35 


\section{INTRODUCTION}

Transformers are an essential part of a modern community's ability to function. Electricity is generated by a power plant and is transported at high voltages through power lines to residential and commercial properties. Each transformer is responsible for stepping the voltage down from a higher transportation value to a lower value for residential and commercial accommodation. Without transformers, electricity use in the commonplace would be more dangerous due to the higher voltage and less cost effective because of the heat generated by line resistance.

The process of stepping voltage down from a higher to lower value is a classic application of electrical engineering. An alternating current present on a conductive wire induces a magnetic field in the vicinity of the current. If a second conductor is placed in the field generated by the first conductor, a current is induced in the second conductor. Current is transferred from one conductor to a second by the utilization of a magnetic field(Harlow 2004).

Permeability is the quantitative ability of a material to carry a magnetic flux, measured in Newtons per Ampear squared $\left(\mathrm{N} / \mathrm{A}^{2}\right)$. Steel is commonly used in transformers to carry the magnetic flux from the higher voltage wire to the lower voltage wire, because 
of steel's high permeability(Harlow 2004). Wire from the source current of higher voltage is wrapped around the steel core for a certain number of turns, and the out wire carrying current to customers at a lower voltage is wrapped around the same core for a certain number of turns. The number of turns around the core is a factor that contributes to the determination of voltage of the second wire.

As with any process, the efficiency of power transfer between the two voltages is not perfect. A considerable loss of energy is seen in the form of heat, due to the resistance of the current by the Joule-effect. If too much heat is generated by the current and resistance of the wires, it can cause the transformer to break down due to the rapid changes in temperature of the materials. It is for this reason and several others that an insulator is present in the transformer tank. The most common insulator used in today's residential pole transformers is a highly refined mineral oil. A light viscous mineral oil is used to transfer heat from the hot core and core windings to the tank wall, where heat travels through the steel tank wall by conduction and is cooled by the surrounding(s), air and wind convection currents. The mineral oil serves not only as a medium for heat transfer, but also as an insulator to protect the circuit's from exposure to elements such as water. The oil serves to keep water from the live currents in order to prevent arcing during normal operations. As the temperature of the oil in the transformer tank rises, the presence of convection currents can be noted, which increase the heat transfer capabilities of the mineral oil.

The voltage at which a transformer breaks down is called the dielectric breakdown voltage. With the addition of nanoparticles to the coolant, the dielectric breakdown voltage can be raised so that the transformers can operate at a higher voltages if desired. Using a 
volume fraction of nanoparticles up to $0.8 \%$, a rise greater than $300 \%$ has been obtained in the dielectric breakdown voltage of a transformer, when compared to the dielectric breakdown voltage using the base transformer oil as a coolant(Lee, Lee et al. 2012).

Transformers often break down due to an overload in heat. Repairing a transformer is a dangerous and cost intensive project due to the amount of current and resources needed for the job. From 1997 to 2001, there was a reported total of $\$ 286,628,811$ worth of damage business loss due to the failure of transformers, and over half of the incidents were directly related to the overheating and fire of the insulation(P.E. 2003). From the staggering aforementioned cost of failure alone, there is reason to investigate solutions to the transformer heating problem. A solution to these expensive breakdowns is to change the system of the transformer to prevent the thermal break downs, one way to accomplish this is to increase the ability of the mineral oil to transfer heat.

A field of research orientated around colloid suspensions has emerged over recent years. One significant application of this research is the discovery of the enhancement of the heat transfer capabilities of common coolants. For example, addition of $4 \%$ volume fraction of Copper Oxide nanoparticles to Ethylene Glycol results in a $20 \%$ increase in the thermal conductivity by some studies (Eastman, Choi et al. 2001). With results like this in mind, the addition of nanoparticles to mineral oil can potentially increase the transfer of heat inside of transformers and reduce the chances of transformer break down from heat overload.

The issue of dispersing the solid nanoparticles in suspension is an important thermodynamic and transport consideration. When the solid nanoparticles are first introduced into the base fluid, the solid nanoparticles tend to aggregate together, forming 
an undesirable two phase system of solid nanoparticle clusters and the liquid. On the molecular level, the solid nanoparticles are present together, and the mineral oil molecules cannot penetrate the solid nanoparticle clusters in order to separate the individual nanoparticles. To overcome this, an ultrasonic vibrator is used to break up the large clusters of nanoparticles and help disperse them more evenly into the base fluid(Xuan and Li 2000), mineral oil in this case. In order to help keep the solute suspended in the mineral oil, a surfactant is often used to inhibit the molecular interactions between solid nanoparticles and to further prevent the agglomeration of nanoparticles into clusters.

Heat capacity is an important thermal parameter that changes with the temperature of the suspension and the presence of nanoparticles in the suspension. Recently a calorimeter has been used to measure the specific heat capacity of a nanoparticle enhanced suspensions, the results of the test shows that the specific heat capacities of nanofluid are not the same as those of the base fluids. The largest factors that seem to change the heat capacities are the nanoparticle size and volume concentration of the nanoparticles in the enhanced suspension(Zhou, Wang et al. 2010).

The heat capacity of metals oxides and metals on average are lower than that of organic and other small molecules according to some estimation research (Leitner, Chuchvalec et al. 2002, Gibbs 2013). It takes less energy to increase the temperature of metals/metal oxides compared to organic molecules, such as mineral oil. Based on a weighted average by volume fraction addition of solid nanoparticle metals and metal oxides, adding nanoparticles will not significantly decrease the heat capacity of the nanofluid if the percentage of nanoparticles present in the nanofluid is small( $(0.1 \%-25 \%)$. Significant work has been done on the prediction of heat capacity with nanoparticle 
addition.(Zhou, Wang et al. 2010). Some of the research suggested that one method for the prediction of heat capacity of a nanofluid is to use a simple weighted average between the nanoparticles and the base fluid, as shown in Equation 1 below.

$$
c_{p, n f}=(1-\varphi) c_{p, f}+\varphi c_{p, n p}
$$

Where $\varphi$ is the volume fraction of nanoparticles added to enhance the base fluid, $c_{p, f}$ is the heat capacity of the base fluid, $c_{p, n p}$ is the heat capacity of the nanoparticle, $c_{p, n f}$ is the heat capacity of the nanoparticle enhanced fluid.

Nanoparticle enhancement of base fluids for increased thermal conductivities can be applied in more than one scenario than just heat transfer enhancement of mineral oils. The nanoparticle enhancement of various coolants has obvious applications with heat exchangers. Adding solid metallic nanoparticles to coolants used in heat exchanges can increase the heat transfer efficiency of heat exchangers, but also has an effect on the thermodynamic generation of entropy for this operation(Elias, Miqdad et al. 2013).

Probably the most significant parameter that changes with the addition of nanoparticles is the thermal conductivity coefficient, $\mathrm{k}$, modeled for conduction in Equation 2 below: 


$$
Q=\frac{k \times \Delta T}{x}
$$

Where $\mathrm{Q}$ is the amount of heat being transported, $\mathrm{x}$ is the distance that heat is travelling, and $\Delta \mathrm{T}$ is the temperature gradient between the heat source and the heat sink. Metals are known for having a higher thermal conductivity constant than common organic materials, like oils. The fact that metals have higher thermal conductivity constants $(\mathrm{k})$ is partly due to the fact that metals have delocalized electrons.

Several different methods are used to measure thermal conductivity values in the lab, such as the guarded hot plate, the hot wire technique, or by laser flash diffusivity. The guarded hot plate technique is an equilibrium process where a solid sample is placed between two temperature controlled plates. While one plate is heated and the other is cooled at constant rates, the temperature is measured until steady state conditions are evident and then the thickness of the sample and the required Q input is used to calculate thermal conductivity. The hot wire technique places a wire into a fluid, and a constant $\mathrm{Q}$ is supplied through the wire and heat then penetrates into the fluid radially. Several mathematical models exist for the calculation of thermal conductivity from the temperature measurements and estimates of the wire and the fluid container's wall. The laser flash diffusivity supplies heat to the sample by a laser one side, and an infrared thermometer is used to measure the temperature change on the opposite side of the laser. Depending on 
the properties of the material known, the thermal diffusivity and the thermal conductivity can be calculated by this testing method(Ltd. 2014).

The addition of nanoparticles to the light mineral oil should significantly enhance the thermal conductivity of the mineral oil. It has been shown that a nanoparticle volumetric addition of $5 \%$ of the base fluid volume can increase the thermal conductivity $45 \%$ when compared to the base fluids(Murshed, Leong et al. 2008). A weighted average of the thermal conductivities based on volume fraction would not result in a $45 \%$ increase in the average thermal conductivity constant $(\mathrm{k})$; this significant increase in the thermal conductivity is reason enough to pursue the understanding of the mechanism for increased heat transfer.

The mechanism for why heat transfer enhancement occurs with the addition of nanoparticles is currently not completely understood or known. The most commonly accepted mechanism is one that includes the Brownian motion of the metal oxide nanoparticles, considerations of the flow conditions, properties of the nanoparticles, and particle and clustering size (Keblinski, Phillpot et al. 2002).

Brownian motion is a topic that is introduced when discussing the molecular interactions between particles. Brownian motion is the random motion of particles that occurs from various collisions with other molecules. Consider a solid Copper Oxide nanoparticle suspended in mineral oil. As the solid particles exist in the mineral oil suspension, it possess its own energy level, with a specific kinetic energy of rotation and thermal energy of vibration. As the particle is suspended in the oil, molecules of the liquid interact with the solid particle. Interactions can include reactions, collisions, or secondary bonding forces such as Van der Waals, but for the transformer model only interactions by 
collisions will be considered, due to the lack of necessary electronics for reacting and Van der Waals forces. As molecules from the liquid interact with the solid nanoparticle, energy is transferred during each interaction and collision, changing the level of energy of the solid nanoparticle for each collision. The more collisions that take place suggest a more uniform level of internal energy throughout the colloidal suspension of solid nanoparticles and liquid molecules, reaching a thermal equilibrium.

Flow conditions also play an important role in the molecular interactions of solid nanoparticles dispersed in mineral oil. Under laminar flow conditions (lower flow rates and Reynolds numbers), the molecular interactions of molecules is higher than if the nanofluid was still. Under turbulent flow conditions (higher flow rates and Reynolds numbers), the molecular interactions of molecules is higher than if the nanofluid was under laminar flow conditions. Supposedly a higher flow rate will show increased molecular interactions between nanoparticles and molecules of the base fluid.

Although the Brownian motion and flow conditions play an important role in the heat transfer enhancement with regards to the molecular interaction mechanism, recent research believes that these two phenomena do not affect the heat transfer enhancement as much as particle size and shape(Murshed, Leong et al. 2008). An individual solid nanoparticle $(40 \mathrm{~nm})$ is very large compared to a mineral oil chain molecule (1.5 3.0 nm). Linear agglomeration of particles results in higher thermal conductivity. Instead of individual solid nanoparticles covered in a surfactant, as the Brownian motion model depicts, giving the largest contribution in the thermal conductivity enhancement, the particle and agglomeration size is suggested to be the largest factor for thermal conductivity 
enhancement. Larger chained agglomerations without surfactants has been shown to increase the thermal conductivity of the nanofluid(Keblinski, Prasher et al. 2008).

Enhancements in heat transfer capabilities have been found in varying types of nanofluids, even in suspensions with very small volumetric particle loading, approximately $<5 \%$ (Murshed, Leong et al. 2008). The nanoparticle parameters which seem to repeatedly make significant differences in the heat transfer abilities of the nanofluid are size, shape, and material of the nanoparticles. Nanofluids with metallic nanoparticles have been found to possess higher thermal conductivity values when compared to nanofluids with oxide nanoparticles. Smaller nanoparticles sizes have shown higher heat transfer capabilities and nanoparticles that are rod-like have shown higher conductive heat transfer capability than spherical nanoparticles(Murshed, Leong et al. 2008).

The name "mineral oil" is a broad term that can be used to describe several different types of oil. Mineral oil is a distillate of petroleum and typically has carbon alkane cyclic compounds and chains anywhere from fifteen to forty carbons in length. The properties of mineral oil as a whole can vary with the concentrations of various molecules in the oil, for example an oil with considerably longer carbon chains would have a larger viscosity than a mineral oil with considerably shorter chains. The mineral oil used in this experiment is a lighter viscosity mineral oil. The rational of using a lighter viscosity mineral oil instead of a heavier viscosity oil is simply the resistance to convection. As the heat starts to build up in the oil and the main heat transfer mechanism goes from conduction to convection, a lighter viscosity mineral oil offers less resistance to a convection current and therefore has a better coolant property in regard to ease of convection current buildup, in the experimental cell or the transformer. The lighter viscosity mineral oil and the addition of 
the nanoparticles to the mineral oil should increase the heat transfer capabilities of the coolant that can be used in a transformer, and by extension reduce the likelihood of a transformer failure from heat overload.

There are two purposes of this research, to design and build a heat transfer cell that could accurately measure the heat transport coefficients of various fluids and to determine if the increased heat transfer capabilities of nanofluids can be applied to cooling transformers. If a stable suspension of nanofluid can be obtained, the instrument for measuring thermal conductivity and convection coefficients was meant to measure the heat transfer enhancement of the nanofluids. After reviewing the work of various research in the nanofluids community and how individuals commonly measure thermal conductivity today, several nanofluid suspensions were attempted and measuring instruments were constructed and tested. 


\section{METHODS AND MATERIALS}

One goal of this project was to apply the heat transfer enhancement of nanofluids to a transformer. In order to gain a better understanding of how this technology would be used in the field, an experimental set up was designed with parameters and conditions similar to a common transformer.

In order to test this application of heat transfer enhancement in regards to use in transformers, a direct current source meter was used to provide energy to a system analogous to a residential pole transformer. A direct current source meter (BK PRECESION 1761) was used to provide current to a Nichrome Wire (14 AWG from McMaster-Car), a well-known resistance wire, suspended in mineral oil, or other fluid. The mineral oil, or any heat transfer fluids mentioned below, is contained in a vertically suspended copper pipe that has a loose copper cap on the top and a soldered copper cap on the bottom. The copper pipe is 6" in length and varies in diameter based on the experiments performed. The copper caps have holes for the Nichrome wire to fit through, and the top copper cap has an additional hole to relieve any pressure built up in the copper tube, making the pressure inside the tube approximately atmospheric. The Nichrome wire is insulated where it makes contact with the copper pipe, in an effort to reduce the current moving throughout the copper pipe. On the surface of the copper pipe, there is a drilled indent 
roughly the thickness of the pipe wall to represent a thin plane of copper that is the inner wall of the copper pipe. A T-type thermocouple is placed on the indent to read the assumed temperature of the inner wall while another T-type thermocouple is placed on the Nichrome wire above the top insulation to represent the temperature of the wire (transformer core). The described transformer cell system is illustrated in Figure 1 below.

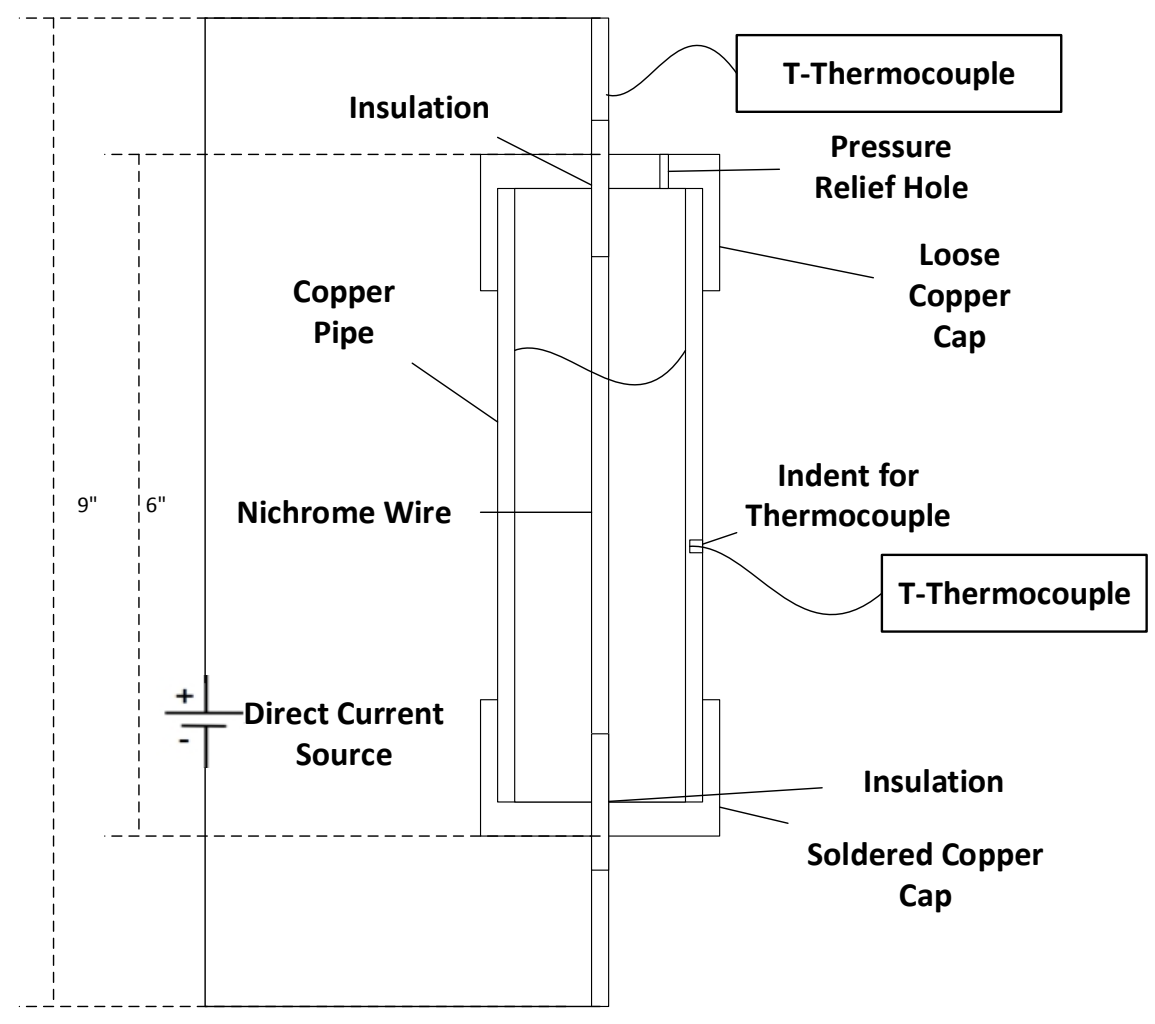

FIGURE 1-ILLUSTRATION OF FIRST EXPERIMENTAL HEAT TRANSFER CELL

There are several pipe diameters to choose from, to model various transformer tanks and the thicknesses of the heat transfer medium, mineral oil, from the core to the wall of the transformer tank. As the wire conducts the current from the source meter, the resistance of the Nichrome will generate heat by the Joule effect. The heat is then transferred from 
the wire to the wall of the copper pipe by convection and conduction heat transfer mechanisms.

The maximum distance between a transformer's core and the wall is on average two inches ${ }^{1}$. Heat is transferred from the transformers hot core to the wall by either conduction or convection. In order to determine roughly where a crossover from conduction to convection occurs, several experiments were conducted that varied the distance from the heat source to the heat sink. Experiments were conducted in copper pipes of diameter $1 / 4,, 1 / 2 "$, and $1 "$.

In this scenario, the heat source of the steel core of a transformer is represented by the Nichrome wire, the distance that the heat travels is comparable to the distance between a transformer's core and steel pot's wall. The mineral oil used is a light viscosity mineral oil, able to achieve convection currents more readily than a thick viscous mineral oil. The light viscosity of the mineral oil is desirable for conditions in a transformer tank and heat transfer cell because the lighter viscosity will allow for the faster development of convection currents, which are ideal for heat transfer(Srinivasan and Saraswathi 2012). The model mentioned above should be a good comparison to a common residential pole transformer.

Due to some questionable results and the possible error mentioned from the two assumptions above, a second design was implemented for experimentation. This second design is very similar to the apparatus shown in Figure 1, with the major difference being the location of the thermocouples. For the thermocouple that reports the wall temperature,

\footnotetext{
${ }^{1}$ The two inches number was provided by a well-known transformer manufacturer in the United States of America.
} 
a small hole was drilled into the side of the copper pipe, and a thermocouple was placed just inside the hole. The thermocouple was then sealed with a silicone spread to prevent any leakage. The thermocouple that represents the wire temperature was placed inside the cell at the same height as the thermocouple inside the wall. The wire thermocouple was adhered to the wire by a thermally conductive cement provided by OMEGA. The wire thermocouple was also placed on the opposite side of the wire from the wall thermocouple, so that the heat travelling radially from the wire to the wall would not encounter any added resistance from the thermally conductive. A diagram of this second apparatus can be seen in Figure 2 below.

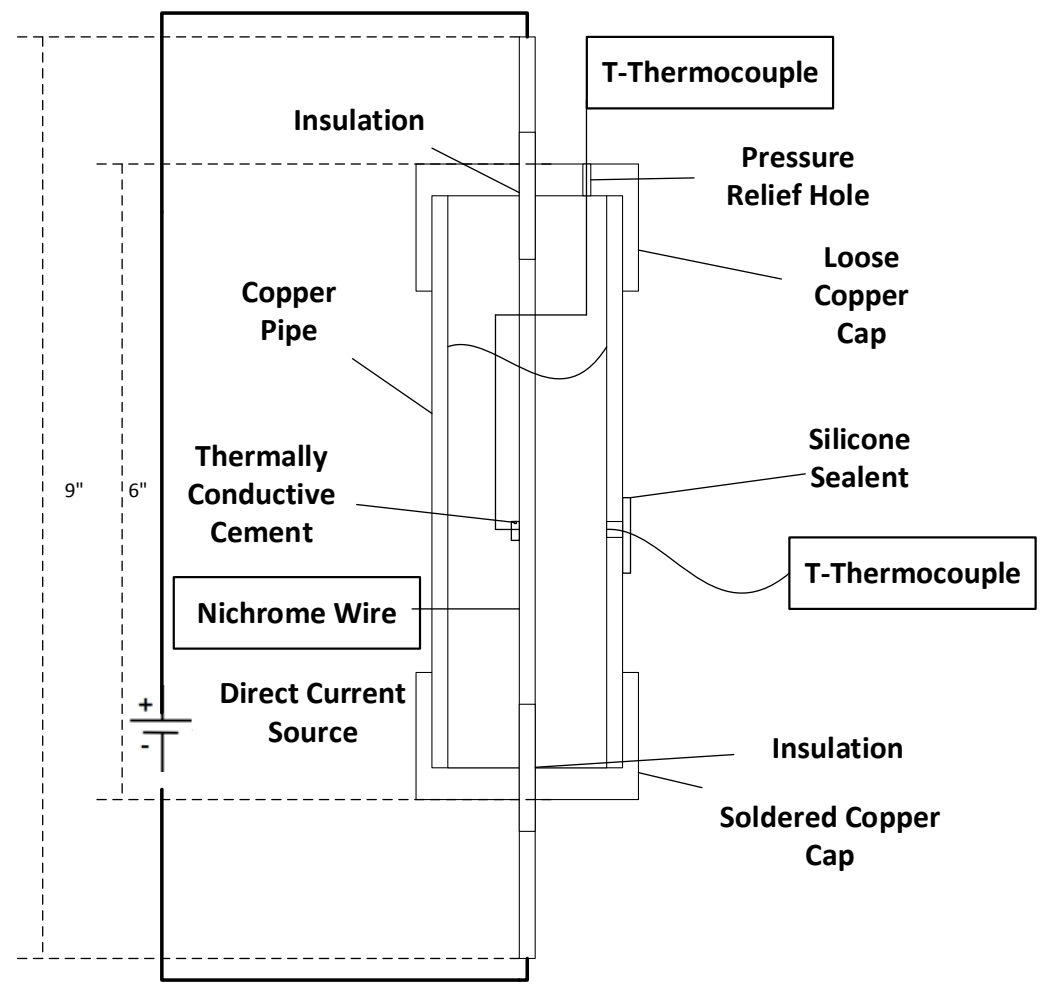

FIGURE 2-ILLUSTRATION OF SECOND EXPERIMENTAL HEAT TRANSFER CELL 
One interesting facet about this second experimental heat transfer cell is that the temperature of the wall and the wire are being directly measured. Some lab scale instruments are designed to estimate the temperature of the wire, which may introduce some error into the accuracy of the instrument. The change in thermocouple placement is essential for contributing to the elimination of error in the second experimental heat transfer cell. By placing the thermocouples directly on the wire and the wall, this instrument in some ways is more accurate than some lab scale instruments.

There were three types of fluids used in these experimental apparatuses to test the accuracy of the results obtained: DI water, AMSOIL 0W-30 Synthetic Motor Oil, and a light viscosity mineral oil. The DI water used is common quality de-ionized water that can be found in many labs. The AMSOIL 0W-30 Synthetic Motor Oil was unused motor oil and was opened from a new container of oil, the oil has a light amber color and other details about it can be found on AMSOIL's website ${ }^{2}$. The light viscosity mineral oil was purchased from McMaster-Car and was produced by the W. S. DODGE OIL Co. under the name WHITE OIL LIGHT.

Two nanopowders were used in attempt to create a stable nanofluid. The first nanopowder used was Copper Oxide $(\mathrm{CuO})$ nanoparticles 40nm in diameter and nearly spherical. The Copper Oxide nanoparticles were purchased from SkySpring Nanomaterials in Texas. Copper Oxide nanoparticles were initially chosen for this experiment for several reasons. Copper Oxide nanoparticles had been used in nanofluid suspensions before and shown a heat transfer enhancement in coolants like Ethylene Glycol

\footnotetext{
${ }^{2}$ http://www.amsoil.com/shop/by-product/motor-oil/gasoline/sae-0w-30-signature-series-100-percentsynthetic-motor-oil/
} 
at small volume fractions (Kwak and Kim 2005, Srinivasan and Saraswathi 2012) and have been shown to have higher heat transfer enhancement versus Silica and Aluminum nanofluids(Yulong Ding and Yurong He1 2007). Copper Oxide also does not show significant magnetic behavior in a magnetic field, this is important because the strong magnetic field in a transformer could potentially effect the flow patterns of nanoparticles and diminish the heat transfer enhancement observed(Tomčo, Marton et al. 2006). It is advantageous to use a nanoparticle like Copper Oxide that does not trap charges as compared to other nanoparticles that can trap charges and cause a thermal break downs if the relative humidity becomes too high(Du, Lv et al. 2012). At the planning stages of this experiment, Copper Oxide had not been tested for compatibility with mineral oil for transformer cooling or very few results have been published(Choi, Yoo et al. 2008). The Copper Oxide nanoparticles were used in conjunction with a well-known surfactant cetyltrimethylammonium bromide, $\mathrm{CTAB}$, in order to enhance the stability of the nanofluid(Murshed, Leong et al. 2008, Rucker 2011). The second nanopowder used in this experiment was a carbon coated copper nanoparticle $25 \mathrm{~nm}$ from US Research Nanomaterials, and spherical in morphology.

In order to record data more efficiently and regularly, an automatic data logger was used throughout this experiment. The Reed SD-947 4-Channel Data Logger was used throughout this experiment in order to provide accurate and consistent data. This data logger from Reed was chosen because it has the ability to record data from four different thermocouple ports, seeing how each experiment would take two thermocouple readings, it was convenient to be able to perform more than one experiment at a time. One feature used from this data logger is the ability to change the time interval where data was taken 
from every second, to every two seconds, to every five seconds, to every 15 seconds a data point and so forth. The time interval was chosen based on the length of experiment and how many data points the data logger could record onto the Excel sheet and the removable SD memory card, average time intervals were from one to three hours to reach steady state conditions. Another reason this data logger was chosen is because it can read a variety of thermocouples, which allows its use in a larger temperature range and more likely to be used in the lab for subsequent experiments. 


\section{A. Procedures For Nanofluid Preparation}

Following is the procedure for preparing the nanofluid by the two step approach(Yu and Xie 2012):

1. Weigh out amount of the base fluid to be used

2. Determine weights of nanoparticle and surfactant(optional) to add for desired weight percentage of nanoparticle

3. Add predetermined surfactant amount to the base fluid

4. Add predetermined nanoparticle amount to the mixture

5. Sonicate at $65 \%$ amplitude for 30 minutes

a. Optional: Sonicate in an ice bath to prevent excessive heating of the nanofluid 


\section{B. Procedure for Experimental Heat Transfer Cell Operation}

Following is the procedure for the experiment with the heat transfer cells:

1. Check to ensure that the inside of the copper cell and the wire is clean and that the seals are working by rinsing out the cell with DI water or the base fluid

2. Fill to the copper cell completely with the fluid being tested

3. Put the loose copper cap on top of the copper cell and the Nichrome wire

a. Plug in the thermocouples into the Reed SD-947 Data Logger and record which ports the thermocouples are located. If using the first heat transfer cell, tape the wire thermocouple to the Nichrome wire above the insulation and the loose copper cap. Ensure that there is direct contact between the thermocouple and the Nichrome wire

4. Connect the positive and negative electrodes to the Nichrome wire and the direct current source meter (BK PRECESION 1761)

5. Format the SD card in the Reed SD-947 Data Logger, with the data logger's software, for recording data

6. Set the thermocouple type on the data logger to type T

7. Set the time interval set point to the desired value

8. Optional: Wait for the wire and wall temperatures to read the same temperature, or use a fan to cool the thermocouples to the same temperature 
9. Start recording data on the Reed SD-947 Data Logger while simultaneously turning on the direct current source meter (BK PRECESION 1761) to the desired Voltage and Amperage

10. Wait for equilibrium to be reached

11. Optional: Step the Voltage and Amperage to the desired value and repeat the previous step

12. Stop data logging and turn off the Reed SD-947 Data Logger and then turn off the direct current source meter (BK PRECESION 1761)

13. Download the recorded data from the Reed SD-947 Data Logger's SD card

14. Disconnect the electrodes from the direct current source meter (BK PRECESION 1761) and the Nichrome wire.

15. Dispose of the fluid in the heat transfer cell rinse out with DI water or the base fluid for the next experiment

The experiments which followed these procedures all varied based on the type of experiment conducted. Throughout all of the experiments, the time to wait until equilibrium varied from approximately one to three hours. Some experiments were done in seven steps of supplied q, while other experiments were done in one step or three steps. The steps for the various experiments and their respective approximate q values are given in Table I below. 
TABLE I

VALUES FOR SUPPLIED q AND STEPS FOR EXPERIMENTS

\begin{tabular}{|c|c|c|}
\hline Steps & Step & $\mathbf{q}$ (Watts) \\
\hline 1 & 1 & 2.15 \\
\hline \multirow{3}{*}{3} & 1 & 0.20 \\
\cline { 2 - 3 } & 2 & 0.90 \\
\cline { 2 - 3 } & 3 & 2.15 \\
\hline \multirow{4}{*}{7} & 1 & 0.05 \\
\cline { 2 - 3 } & 2 & 0.20 \\
\cline { 2 - 3 } & 3 & 0.45 \\
\cline { 2 - 3 } & 4 & 0.80 \\
\cline { 2 - 3 } & 5 & 1.25 \\
\cline { 2 - 3 } & 6 & 1.80 \\
\hline
\end{tabular}




\section{RESULTS AND DISCUSSION}

Throughout the course of this experiment, several changes in the design and process were implemented due to the poor results obtained. Data was collected by the Reed data logger described in the previous section, analyzed for a steady state operation, and then evaluated with the various equations mentioned below to determine the thermal conductivity, $\mathrm{k}$, and the natural convection coefficient, $\mathrm{h}$, for the individual experiments. During the course of all the experiments, the time of waiting until equilibrium was reached fell between one to three hours, data for temperature was then averaged over a period of time to represent the equilibrium values. A summary of the most significant experiments and discussion of results can be found in this section.

In the model described in Figure 1, there are two very important assumptions to consider. The first major assumption being that the thermocouple that represents the temperature of the wall is accurate. Although the copper pipe wall is drilled to be very thin where the thermocouple is, it is difficult to have the thermocouple sit in the indent even after the thermal conductivity paste is used to adhere the thermocouple to the wall. So the temperature reading from that point may be lower than the true value for the inside wall temperature due to the increased thermal resistance, and thus error can be introduced by this assumption. 
The second major assumption when considering the first heat transfer cell design is that the temperature reading from the thermocouple at the top of the cell is a good representation for the temperature of the wire inside the cell. In order to determine if the observed wire temperature was a good representation of the temperature of the wire inside the cell, a small experiment was conducted to determine if there is a temperature distribution of in the wire. Thermocouples were attached at various lengths of a bare Nichrome wire the same length as those used in the experimental copper cells, and a measured current similar to that used in the experiment was sent through the Nichrome wire. Results showed that there was not a significant temperature distribution through the Nichrome wire for this experimental design, but still introduced some amount of error by placing the thermocouple outside of the heat transfer cell and not directly onto the Nichrome wire.

The energy of the current running through the Nichrome wire is directly related to the heat generated by the Joule effect, a larger current leads to more resistance and ultimately more heat generated. Some of the experiments described here are either multistepped experiments, where the total heat generated is stepped up to a maximum value, or single-stepped experiment, where the total heat generated is set to the maximum value at the beginning of the experiment. The multistep experiment is advantageous because one can see the thermal conductivity and convection coefficients change as a function of the temperature of the heat source. The single step experiments are convenient especially with the nanofluids. When trying to suspend the nanoparticles, the single step experiments build convection currents faster than the multistep experiments because the single step 
experiments reach a higher temperature in a shorter time frame. This presence of convection currents is advantageous when trying to keep the nanoparticles in suspension,

The hot wire technique is a good method for determining the thermal conductivity of fluids. One reason is that the design allows for the utilization of the wire to work as both a heat source and a temperature sensor, some lab scale equipment utilizes this fact when calculating the transport coefficients. To solve for thermal properties like the thermal conductivity with the hot wire method, it is assumed that the wire heat source is long with a uniform temperature distribution, within an "infinite" test sample(Alvarado, Marín et al. 2012). The more important assumption is that the temperature differences in the heat transfer cell are solely a result of the heat transfer by conduction from the hot wire.

In order to calculate the thermal conductivity, $\mathrm{k}$, of the various liquids in this experiment, Equation 3 below was used. This equation is a well-known tool for many researchers utilizing the hot wire method in their labs (Xuan and Li 2000, Alvarado, Marín et al. 2012).

$$
\Delta T=\frac{q}{4 \pi k} \ln \left(\frac{4 t \alpha}{r^{2} C}\right)
$$

Where $\Delta T$ is the difference in temperature between the wire and wall and is given by the thermocouple readings during the experiment. The variable $k$ is the thermal conductivity of the fluid being tested. The radius of the pipe, the distance between the wire 
and the wall, is $r$. The variable $C$ is a representation of Euler's constant, $\ln (C)=0.5772$. The time $t$ is the time it takes for the temperature to reach equilibrium.

One important assumption for the results of Equation 3 to be valid is Equation 4 below is satisfied.

$$
\frac{r^{2}}{4 \propto t} \ll 1
$$

Seeing that Equation 4 is satisfied is a key restraint on the hot wire equation and is evidence that either conduction or convection is the major mechanism for heat transfer. Equation 4 compares the distance that the heat travels between the heat source and sink, represented by $r^{2}$, to the penetration distance of the heat in the system, represented by $4 \alpha \mathrm{t}$ and is essentially an effective penetration depth. This equation compares what distance the heat can actually penetrate to what the distance between the heat source and sink is. If the equation is less than one, then the heat is penetrating further than the fluid thickness and passes the system boundaries, a strong case for conduction. If the equation is greater than one, then the thickness of the fluid is greater than what the heat can penetrate, leading to the development of convection currents.

The energy flowing through the Nichrome resistance wire is $q$, and $q$ and $\alpha$ are represented by the equations below. 


$$
q=V I
$$

The voltage is represented by $V$. The amperage is represented by $I$.

$$
\alpha=\frac{k}{\rho C_{p}}
$$

The variable $\alpha$ is the thermal diffusivity and is dependent upon the testing fluid and temperature. The density and heat capacity of the fluid is represented by $\rho$ and $C_{p}$. The heat capacity for a test liquid like DI water is readily available from reliable sources on the internet and textbooks; however, for a liquid like mineral oil, the heat capacity is harder to obtain. In order to find a value for the heat capacity of mineral oil, a correlation from Perry's Chemical Engineers' Handbook was used(Green and Perry 2008), page 2185.

$$
C_{p}=A A \sqrt{\rho}+B(T-15)
$$


Where $C_{p}$ here is given in cal/ $(\mathrm{g} \mathrm{C})$ and must be converted. AA and B are correlations for various fluids, for a paraffin base mineral oil AA is 0.425 and B is 0.0009 .

To solve for the thermal conductivity, $\mathrm{k}$, of the test fluid an iterative process was used. All of the experimental data was entered into an Excel formula with an initial guess for $\mathrm{k}$. Excel then varied the value for the thermal conductivity until Equation 4 and Equation 3 were made true. In order to complete the calculation for the thermal conductivity $\mathrm{k}$, the initial guess must be in the same order of magnitude as the true value of the thermal conductivity. The experiment being performed and the conditions of the experiment affected the validity of the calculated value. In all calculations, there was never a case of multiple values for the thermal conductivity which made Equation 3 and Equation 4 true.

For the calculation of the convection coefficient, h, Equation 8 below was used.

$$
h=\frac{V I}{\Delta T A}
$$

Where $\mathrm{A}$ is the surface area for heat transfer, for this case the surface area of heat transfer between the source and the sink is the surface of the Nichrome wire, $A=\pi D L$. Since all of these values are readily available and recorded, the calculation for the 
convection coefficient, h, is very simple. Using Equation 8, the experiments conducted where we expected the presence of convection yielded values for $\mathrm{h}$ in the correct range, 50-1000 $\frac{W}{m^{2} C}$ according to Incropera(Incropera, Dewitt et al. 2007).

In the initial stages of designing this experiment, it was realized that there would be some transition between the heat transfer mechanisms of conduction and convection before two inches between the transformer core and wall had been reached. Several pipe diameters for the heat transfer cells had been chosen to determine where the transition from conduction to convection would occur. From the results of experiments seen in Table II, it is reasonable to conclude that there is only conduction present in the $1 / 4$ " diameter heat transfer cell, and convection in the $1 / 2$ " and 1" diameter heat transfer cells below 
TABLE II

DATA FOR MINERAL OIL IN FIRST HEAT TRANSFER CELL

\begin{tabular}{|c|c|c|c|c|c|c|c|c|c|c|}
\hline $\begin{array}{l}\text { Cell } \\
\text { Size }\end{array}$ & Step & $\mathbf{k}\left(\frac{W}{m^{2} c}\right)$ & $\mathbf{h}\left(\frac{W}{m^{2} c}\right)$ & $q(W)$ & Twall(C) & Swall(C) & Twire(C) & Swire(C) & Time(s) & $\frac{r^{2}}{4 \propto t}$ \\
\hline \multirow{7}{*}{$1 / 4 "$} & 1 & 0.130 & 559.335 & 0.036 & 21.75 & 0.05 & 21.85 & 0.06 & 4870 & $6.82 \mathrm{E}-03$ \\
\hline & 2 & 0.122 & 513.320 & 0.161 & 22.90 & 0.01 & 23.44 & 0.09 & 5800 & 6.10E-03 \\
\hline & 3 & 0.165 & 545.710 & 0.392 & 24.77 & 0.08 & 26.00 & 0.15 & 17389 & $1.50 \mathrm{E}-03$ \\
\hline & 4 & 0.159 & 508.120 & 0.702 & 26.97 & 0.10 & 29.34 & 0.24 & 22469 & $1.21 \mathrm{E}-03$ \\
\hline & 5 & 0.163 & 503.130 & 1.104 & 30.04 & 0.08 & 33.79 & 0.21 & 27509 & 9.64E-04 \\
\hline & 6 & 0.162 & 486.007 & 1.619 & 34.55 & 0.23 & 40.25 & 0.59 & 33569 & $7.96 \mathrm{E}-04$ \\
\hline & 7 & 0.185 & 520.375 & 2.075 & 36.73 & 0.14 & 43.55 & 0.41 & 47588 & $4.91 \mathrm{E}-04$ \\
\hline \multirow{7}{*}{$1 / 2^{\prime \prime}$} & 1 & 0.015 & 204.175 & 0.050 & 21.91 & 0.04 & 21.48 & 0.04 & 4230 & 2.07E-01 \\
\hline & 2 & 0.013 & 175.390 & 0.190 & 24.26 & 0.07 & 22.40 & 0.01 & 4980 & 2.07E-01 \\
\hline & 3 & 0.012 & 170.053 & 0.435 & 28.47 & 0.13 & 24.09 & 0.02 & 5510 & 2.07E-01 \\
\hline & 4 & 0.014 & 172.908 & 0.781 & 33.94 & 0.50 & 26.21 & 0.06 & 4550 & 2.07E-01 \\
\hline & 5 & 0.012 & 180.761 & 1.200 & 39.94 & 0.16 & 28.59 & 0.02 & 5270 & 2.07E-01 \\
\hline & 6 & 0.011 & 181.268 & 1.743 & 47.75 & 0.20 & 31.30 & 0.07 & 5850 & 2.07E-01 \\
\hline & 7 & 0.012 & 188.862 & 2.152 & 52.83 & 0.49 & 33.34 & 0.06 & 5090 & 2.07E-01 \\
\hline \multirow{7}{*}{ 1" } & 1 & 0.060 & 168.805 & 0.050 & 21.49 & 0.03 & 22.00 & 0.03 & 4870 & $2.36 \mathrm{E}-01$ \\
\hline & 2 & 0.053 & 162.895 & 0.192 & 22.20 & 0.00 & 24.21 & 0.11 & 5540 & $2.36 \mathrm{E}-01$ \\
\hline & 3 & 0.059 & 166.323 & 0.436 & 23.11 & 0.03 & 27.60 & 0.17 & 4960 & $2.36 \mathrm{E}-01$ \\
\hline & 4 & 0.060 & 175.828 & 0.782 & 24.20 & 0.00 & 31.81 & 0.15 & 4920 & $2.36 \mathrm{E}-01$ \\
\hline & 5 & 0.070 & 186.180 & 1.204 & 25.58 & 0.00 & 36.64 & 0.17 & 4180 & $2.36 \mathrm{E}-01$ \\
\hline & 6 & 0.059 & 198.284 & 1.738 & 27.80 & 0.02 & 42.79 & 0.51 & 4990 & $2.36 \mathrm{E}-01$ \\
\hline & 7 & 0.024 & 227.282 & 2.186 & 28.50 & 0.01 & 44.95 & 0.51 & 11979 & $2.36 \mathrm{E}-01$ \\
\hline
\end{tabular}

The only results from the conduction calculations which made Equation 3 and Equation 4 true were from the $1 / 4$ " diameter heat transfer cell. The values for $\frac{r^{2}}{4 \propto t}$ are much less than one for the $1 / 4$ " diameter cell, and are closer to one for the $1 / 2$ " and 1 " diameter cells. Considering the discussion after Equation 4, this is strong evidence that there is a conduction presence in the $1 / 4$ " diameter cell and more of a convection presence in the $1 / 2$ " and 1 " diameter cell. These values for $\mathrm{k}$ from the $1 / 4$ " diameter heat transfer cell are also in agreement with 
the common value for mineral oil at $25^{\circ} \mathrm{C}$, which is $0.14 \frac{W}{m^{2} \mathrm{C}}$, this instrument showed a thermal conductivity value of approximately $0.16 \frac{\mathrm{W}}{\mathrm{m}^{2} \mathrm{C}}$ at approximately $25^{\circ} \mathrm{C}$. These results show that the thermal conductivity equation is only valid for the $1 / 4$ " diameter heat transfer cell.

The average for the convection coefficient $\mathrm{h}$ in the $1 / 4$ " diameter cell is $519.42 \frac{\mathrm{W}}{\mathrm{m}^{2} \mathrm{C}}$, and the average for $\mathrm{h}$ in the $1 / 2$ " and 1 " diameter cells are $181.91 \frac{\mathrm{W}}{\mathrm{m}^{2} \mathrm{C}}$ and $183.65 \frac{\mathrm{W}}{\mathrm{m}^{2} \mathrm{C}}$ respectively. The convection coefficient values for the $1 / 2$ " and 1 " diameter cells are significantly lower than the convection coefficient value for the $1 / 4$ " diameter cell, this pattern is repeated throughout the course of all the experiments. This pattern also shows that the Equation 8 is only valid for calculating the convection coefficient in the $1 / 2$ " and 1 " diameter pipes. The trend mentioned here and the results of the $\frac{r^{2}}{4 \propto t}$ equation is why it is believed that for mineral oil there is the transfer between conduction and convection between the $1 / 4 "$ to $1 / 2 "$ diameter cells and not at the longer distance of a 2 " radius as mentioned above. Since the convection coefficient values for the $1 / 4$ " diameter pipe are repeatedly and significantly larger than the values for the $1 / 2$ " and 1 " diameter pipe, it is believed that there is only a conduction heat transfer mechanism present in the $1 / 4$ " diameter pipe and that in this case the convection coefficient values for the $1 / 4$ " diameter pipe are not representative of the true convection coefficient value. The results from Table II show that the convection and conduction equations are only valid in their respective distances, and that there is no overlap in validity between the two equations.

These values for $\mathrm{k}$ in the $1 / 4$ " diameter cell in Table II correlate with the known values for mineral oil's thermal conductivity. This agreement is strong evidence of the 
validity of the thermal conductivity values obtained from the $1 / 4$ " diameter experimental heat transfer cell of the first design for fluids like mineral oil. The results shown in Table II were also checked for repeatability for the success of predicting the thermal conductivity values in the $1 / 4$ " diameter cell. The experiment for heat transfer of mineral oil in the $1 / 4$ " diameter cell was repeated in order to ensure the precision of the instrument, and very similar results were obtained and can be seen in Appendix I.

The values shown above for the convection coefficient $h$ of the $1 / 2$ " and 1 " diameter experimental heat transfer cells of the first design are within the expected range for natural convection coefficients. Due to the lack of reported values for natural convection coefficients for various fluids, these values obtained for the $1 / 2$ " and 1 " diameter cells are assumed to be valid because they fall within the expected range of $50-1000 \frac{W}{m^{2} C}$.

During the course of this experiment, there were several attempts to stabilize nanofluids for experimentation. All fluids were prepared using the procedure listed in the Methods and Materials Section. Nanofluids were prepared with Copper Oxide and Carbon coated nanoparticles in mineral oil, all materials are described in the previous section.

Copper Oxide nanoparticles were first attempted to be stabilized in mineral oil. Initially three volume percentages were used with 1 drop of surfactant CTAB, $0.5 \%, 1.0 \%$, and $1.5 \%$ volume as seen in Figure 3 below. 

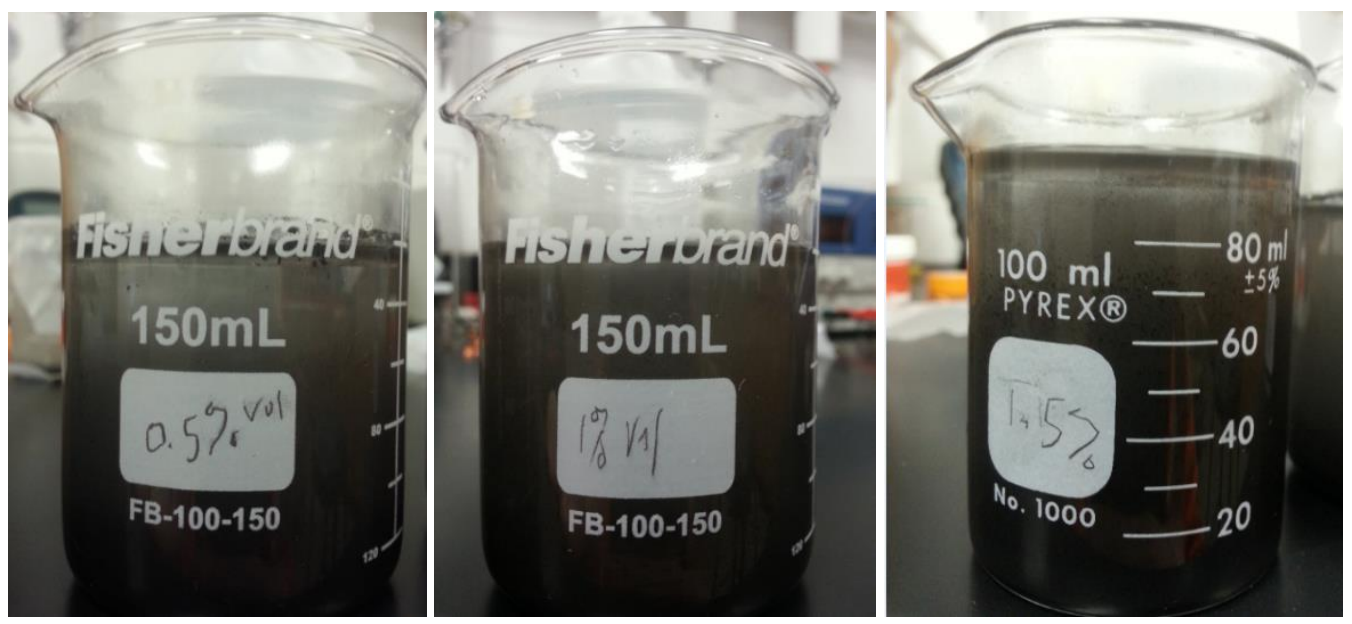

FIGURE 3-CuO NANOFLUID WITH ONE DROP OF CTAB

The images in Figure 3 were all taken approximately 16 hours after sonication. As evident in Figure 3, all three samples are unstable and are unsuitable for testing of this time frame. There is a light cloud near the top of the beaker and the visibility thickens as the view is progressed near the bottom. Although it may appear as the nanoparticles are suspended in the mineral oil near the bottom of the beaker, the nanoparticles are clinging to the interior side of the beaker, and the vast majority of the $\mathrm{CuO}$ nanoparticles are accumulated at the bottom. This behavior of the nanofluid was also observed three hours after sonication.

After acknowledging that the nanofluid in Figure 3 failed to stabilize, another copper oxide nanofluid was prepared with $1 \%$ wt. of the nanoparticle, a significantly lower particle loading. The same procedure in the Methods and Materials section was followed, and the resulting nanofluid after 16 hours of sonication is seen in Figure 4 below. 


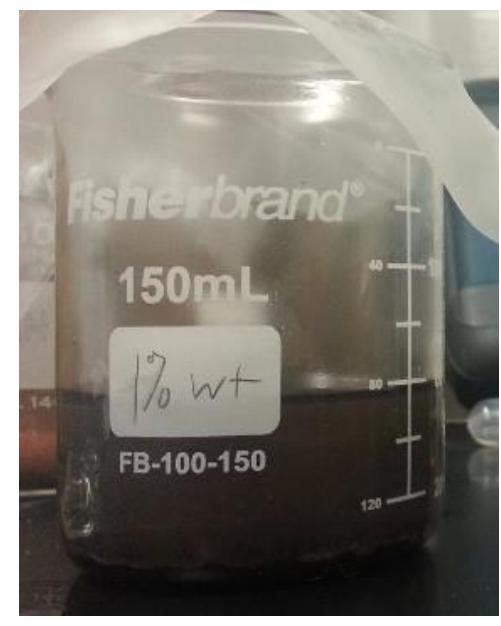

FIGURE 4-CuO NANOFLUID WITH 1 DROP CTAB, 1\% WT

The nanofluid shown in Figure 4 is cloudy with better visibility near the top of the beaker. This is the same result as the nanofluids seen in Figure 3. The nanoparticles accumulate at the bottom of the beaker after a short period of stagnant conditions.

After seeing that the smaller weight percentage of nanoparticles did not yield a stable suspension, varying the amount of surfactant used with the copper oxide nanoparticles was attempted. In the previous attempts, the concentration of the CTAB was approximately $0.5 \mathrm{mM}$, a concentration that was reasonably as low that could be achieved with the equipment and materials available and is similar to other concentrations used with oxide nanoparticles(Murshed, Leong et al. 2008). Due to the equipment limitations, the smallest achievable increase in surfactant is a drop from a pipet. Two more batches of Copper Oxide nanofluid was made with $1 \%$ wt., one with two drops and one with three drops of the surfactant CTAB. The nanofluids after 16 hours are shown below in Figure 5. 


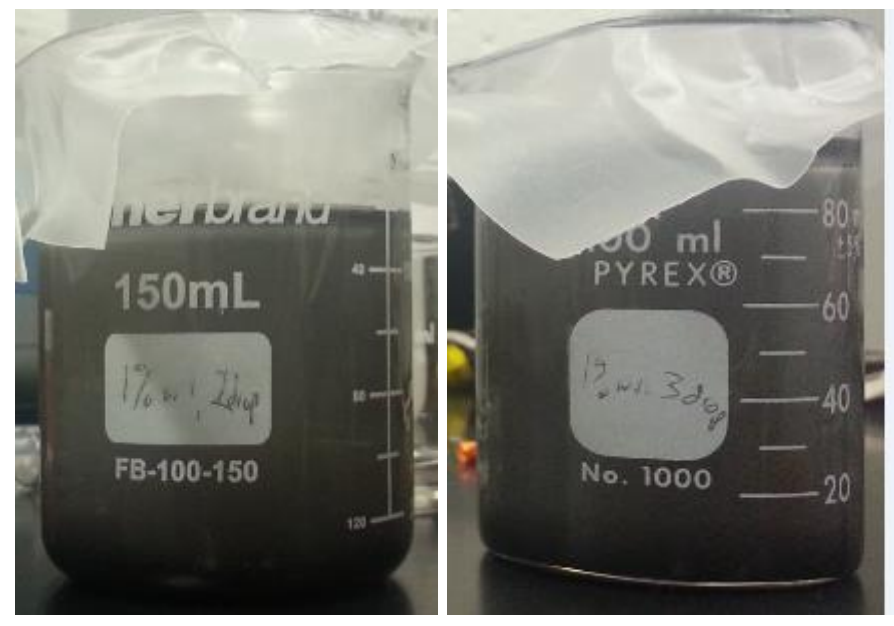

FIGURE 5-CuO NANOFLUID WITH 2 AND 3 DROPS CTAB, 1\% WT

As evident with the other Copper Oxide nanofluids, the nanoparticles cling to the wall of the glass beaker and accumulate at the bottom of the beaker. There is some visibility through the beaker and there is no significant difference between these two samples and the previously discussed Copper Oxide nanofluids.

After several failed attempts to suspend the Copper Oxide nanoparticles into the mineral oil, a 25nm Carbon coated Copper nanoparticle was chosen for experimentation. Believing that the smaller particle size and the organic-organic interface between the Carbon coated Copper nanoparticle and the mineral oil would help stabilize the nanofluid, a $1 \%$ wt. nanofluid without surfactant was prepared by the procedure described in the Methods and Materials section. Unfortunately the nanoparticles began falling out of suspension at the same rate or greater than that of the Copper Oxide nanofluids. One interesting note about this nanofluid is that the nanoparticles that clinged to the edge of the beaker seem to make the nanofluid look stable, as seen in Figure 6 below. It is believed that this phenomenon is due to the nature of the black Carbon coating, the black nanoparticles together block out so much light it seems that the nanofluid is stable. 


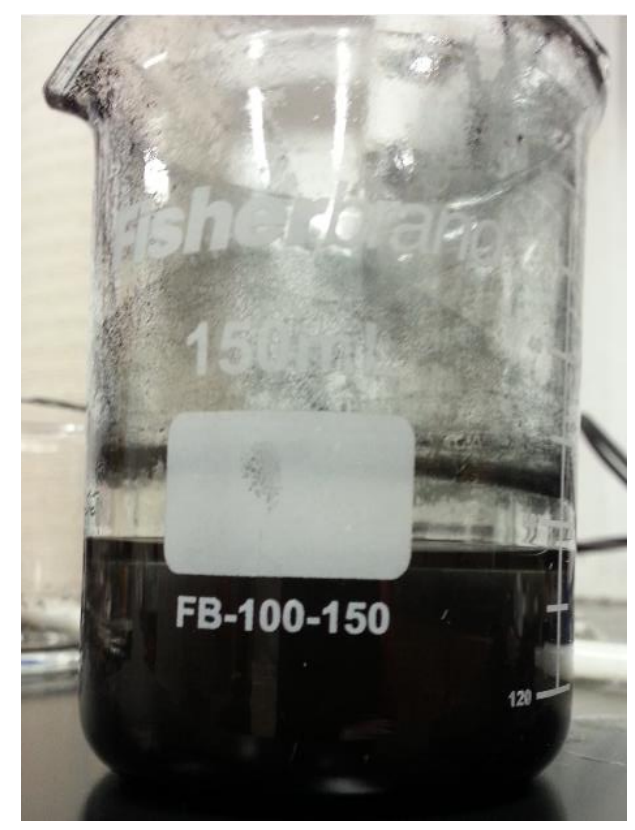

FIGURE 6-CARBON COATED COPPER NANOFLUID

Two different nanoparticles have been tested for their ability to create a stable nanofluid using a light viscosity mineral oil as the base fluid. In all cases and variations of the experiments, the nanoparticles fell out of suspension in a time frame that does not allow for the valid experimentation and determination of heat transfer coefficients like thermal conductivity, $\mathrm{k}$, and convection, $\mathrm{h}$. This is evident by the figures which show the nanoparticles falling out of suspension and the experimental results for thermal conductivity and convection coefficients of the nanofluids, found in Appendix I. One factor that may have a large effect on the suspension of these nanoparticles is density, the density of both of these nanoparticles may be too large for suspension in mineral oil. Both of the nanoparticles shown here are small in diameter, but are very large when compared to small particles like zeolites. These nanoparticles used in this research have been 
stabilized in other oils and fluids, but for the case of conduction and natural convection, the flow conditions do not aid in the stabilization of the nanofluid. Unless the transformer industry would start to make a move away from using a coolant like mineral oil, using Copper Oxide (40nm) and Carbon Coated Copper (25nm) nanoparticles to increase the heat transfer capabilities of mineral oil is not a viable due to the quick destabilization of the nanofluids.

To ensure that the poor results from the heat transfer experiments with the nanofluid was due to the poor stability of the nanofluids and not the error inherent with the measuring instruments, a second design was used to create another heat transfer cell as shown in Figure 2. This second design places the thermocouples in direct contact with their assumed positions to yield more accurate results. To test the accuracy of the experimental heat transfer rig, three fluids were tested; mineral oil, AMSOIL synthetic 0w-30, and DI water. The reported thermal conductivity values for mineral oil, AMSOIL, and DI water can be found in Table III below. 
TABLE III

\section{GENERAL THERMAL CONDUCTIVITY VALUES FOR MINERAL OIL AND}

\section{AMSOIL AND REPORTED VALUE FOR DI WATER}

\begin{tabular}{|c|c|}
\hline Fluid & $\mathbf{k}\left(\frac{\boldsymbol{W}}{\boldsymbol{m}^{\mathbf{2}} \boldsymbol{C}}\right)$ \\
\hline Mineral Oil $^{3}$ & 0.14 \\
\hline AMSOIL $^{4}$ & 0.14 \\
\hline DI Water $^{5}$ & 0.58 \\
\hline
\end{tabular}

The thermal conductivity value for AMSOIL seen in Table III is a general thermal conductivity value for unused engine oil, this value will be used for comparison because there is no reported value for the AMSOIL. The thermal conductivity value for mineral oil in Table III is a general value for transformer oil and may not necessarily be the true value but can be used for comparison with the experimental value for mineral oil. Table IV below summarizes the results from the experimental test with the first and second heat transfer cell designs in the $1 / 4$ " diameter cells and experiments performed in one step.

\footnotetext{
${ }^{3} \mathrm{http}: / /$ www.engineeringtoolbox.com/thermal-conductivity-liquids-d_1260.html

${ }^{4}$ http://www.engineeringtoolbox.com/thermal-conductivity-liquids-d_1260.html

${ }^{5} \mathrm{http} / / / \mathrm{www}$.engineeringtoolbox.com/thermal-conductivity-d_429.html
} 
TABLE IV

RESULTS FROM THE FIRST AND SECOND HEAT TRANSFER CELLS

\begin{tabular}{|c|c|c|c|c|c|c|c|c|c|}
\hline Design & Fluid & $\mathbf{k}\left(\frac{\mathrm{W}}{\mathrm{m}^{2} \mathrm{C}}\right)$ & $\mathbf{q}$ & $\mathbf{T 1}(\mathbf{C})$ & $\mathbf{S 1}(\mathbf{C})$ & $\mathbf{T 2}(\mathbf{C})$ & $\mathbf{S 2}(\mathbf{C})$ & Time(s) & $\mathbf{r 2 / 4 a t}$ \\
\hline First & $\begin{array}{c}\text { Mineral } \\
\text { Oil }\end{array}$ & 0.081 & 2.224 & 52.03 & 0.12 & 40.63 & 0.05 & 9733 & $8.10 \mathrm{E}-02$ \\
\hline Second & $\begin{array}{c}\text { Mineral } \\
\text { Oil }\end{array}$ & 0.099 & 2.042 & 48.00 & 0.01 & 39.04 & 0.05 & 10150 & $9.92 \mathrm{E}-02$ \\
\hline First & DI Water & 0.122 & 2.152 & 46.53 & 0.41 & 39.07 & 0.11 & 17520 & $1.22 \mathrm{E}-01$ \\
\hline Second & DI Water & 0.594 & 2.104 & 37.89 & 0.03 & 36.10 & 0.00 & 10065 & $5.94 \mathrm{E}-01$ \\
\hline First & AMSOIL & 0.109 & 2.224 & 48.13 & 0.13 & 39.20 & 0.00 & 9735 & $1.09 \mathrm{E}-01$ \\
\hline Second & AMSOIL & 0.120 & 2.104 & 46.06 & 0.11 & 38.25 & 0.11 & 9638 & $1.20 \mathrm{E}-01$ \\
\hline
\end{tabular}

As seen in Table IV, the thermal conductivity values for mineral oil has dropped significantly from the beginning of the experiment; however, the mineral oil has been sitting for several months, so it is possible that the quality of the sample has degraded over time.

It is important to note how close in value the thermal conductivity is between the first and second design for the oils, but the thermal conductivity values between the first and second design for DI water are very far apart. This can be explained by the relatively poor thermal conductivity that oil has compared to a liquid like DI water. Most oils have a thermal conductivity of $0.15 \frac{W}{m^{2} C}$, a value very low when compared to DI water's $0.58 \frac{W}{m^{2} C}$. The reason that the thermal conductivity value for the first design's DI water experiment is much lower is due to the fact that DI water is more thermally sensitive to the error because the water can transport heat more efficiently than the oils, this is why the thermal conductivity values for the oils in the first design still were within acceptable ranges of the true value. The oils are not as sensitive to the error due to their relatively 
poor thermal conductivity. Any kind of variance in the current provided by the source meter is recognized better in the experiments using the second design and DI water, because DI water has such a high thermal conductivity it shows the noise of the variance in the heat generated. The experiments using the mineral oil was not as susceptible to error because if the values for the heat generated changed during the experiment, roughly the same amount of heat was transported to the cell wall anyways because the oils were transporting less heat when compared to the DI water. Because the DI water experiments worked with a smaller $\Delta \mathrm{T}$ than the oil experiments, any change in the $\Delta \mathrm{T}$ observed had a large impact on the data and calculated variables.

The mineral oil, AMSOIL, and DI water thermal conductivity values for the second design were all within acceptable ranges of their expected values. If assuming the true thermal conductivity of the sample DI water is actually $0.58 \frac{\mathrm{W}}{\mathrm{m}^{2} \mathrm{C}}$, the error associated with the calculated $0.59 \frac{\mathrm{W}}{\mathrm{m}^{2} \mathrm{C}}$ value is $1.7 \%$, an acceptable range of error for most studies and in the same range of error for instruments of similar design(Nagasaka and Nagashima 1981).

Since the second design was able to calculate the true values of thermal conductivity for the DI water and the oils, the second design is more versatile than the first design. When comparing the calculated values of the thermal conductivity for the various fluids to that of their expected ranges, the success of the heat transfer cells is evident. 


\section{CONCLUSIONS}

There were two purposes of this research, decided at the beginning of these experiments. The first goal was to design and build a heat transfer cell that could accurately calculate heat transport coefficients of various fluids and possible measure the enhancement of heat transfer obtained by a nanofluid. The second goal was to determine if the increased heat transfer capabilities of nanofluids could be applied to cooling transformers.

For the first goal of designing and building a heat transfer cell that could accurately calculate heat transport coefficients of various fluids, there is success. The commonly accepted thermal conductivity value of mineral oil $0.14 \frac{\mathrm{W}}{\mathrm{m}^{2} \mathrm{C}}$ at $25^{\circ} \mathrm{C}$, and is very close to the $0.16 \frac{\mathrm{W}}{\mathrm{m}^{2} \mathrm{C}}$ value that the instrument of the first design yielded at approximately $25^{\circ}$. Seeing how the term mineral oil, can account for variety of different oils, it is accepted that the $0.16 \frac{W}{m^{2} C}$ value obtained is valid. The success of the heat transfer cells is also evident by Table IV, where the heat transfer cell of the second design showed a thermal conductivity of DI water to be $0.59 \frac{\mathrm{W}}{\mathrm{m}^{2} \mathrm{C}}$, which his significantly close to the commonly accepted value of $0.58 \frac{W}{m^{2} C}$. The second heat transfer cell also showed a thermal conductivity value for 
AMSOIL to be $0.12 \frac{W}{m^{2} \mathrm{C}}$ and $0.10 \frac{\mathrm{W}}{\mathrm{m}^{2} \mathrm{C}}$ for mineral oil, both of these values are within the expected ranges of thermal conductivity for oils. The second heat transfer cell design was able to accurately predict the thermal conductivity of the DI water and the oils, which the first design was only able to accurately show the thermal conductivity values for the oils. This is credited to the high sensitivity to error of the DI water because of water's high thermal conductivity. The oils are not as sensitive to the error due to the oil's relatively lower thermal conductivities.

As for the second goal of applying the increased heat transfer capabilities of nanofluids to a transformer cooling application, it is concluded that this is not a viable option for the nanoparticles tested in this research. In the experiments involving Copper Oxide and Carbon coated Copper nanoparticles, no stable nanofluids were obtained using these nanoparticles with mineral oil as the base fluid. Due to the poor stability of the nanofluids produced with mineral oil as the base fluid, the heat transfer enhancement of nanofluids produced by this research is not applicable as a coolant for transformers, unless the transformer industry would make a move to use a more suitable nanofluid base fluid as the coolant or an appropriate nanoparticle can be suspended in mineral oil.

In the end, although the nanoparticles were not able to be suspended in the mineral oil, there is notable success by the design and use of the heat transfer cells. Two heat transfer cells were designed and used to successfully predict the thermal conductivity and convection coefficients of a range of fluids. The materials used to make the heat transfer cells are upwards of $\$ 100$ and is very inexpensive when compared to using a lab scale instrument which can cost thousands of dollars. 


\section{RECOMMENDATIONS}

Several areas of this research can be expanded and built upon to further expand the knowledge of oil-based nanofluids and to ensure that the results gained from experimentation are true and valid to the highest degree.

1. Try several different nanoparticles to gain a stable suspension. There are cases of success with stabilizing a nanofluid with mineral oil as the base fluid, for example using Hexagonal Boron Nitride nanoparticles(TahaTijerina, Narayanan et al. 2012). I tried two different density materials, but it is possible that the density was not low enough for suspension in mineral oil. It should be worthwhile to try a zeolite nanoparticle or even nanoparticles smaller than $25 \mathrm{~nm}$, which is the smallest nanoparticle used in this research.

2. Be accurate with the fluid properties, like heat capacity, used for calculation of thermal properties. When testing for the thermal conductivity of a nanofluid with the devices described in this paper, measure the heat capacity of the nanofluid or any fluid being tested and use the measured value in the calculations. During the course of the experiment I found that whether or 
not valid results were obtained could be dependent upon entering in the correct heat capacity and other properties.

3. Try using a material besides copper for the heat transfer cell. Although copper is thermally conductive, it may be that some interactions between the copper cell and the copper nanoparticles could have contributed to the error of the nanofluid experimentation.

4. Increase the temperature range of experimentation. Although the range of temperatures used in this experiment are valid for research, it would be good to see if any of the data would change at temperatures similar to those found in common pole mounted transformers. 
APPENDIX I 
TABLE V

HEAT TRANSFER RESULTS FROM NANOFLUID EXPERIMENTS

\begin{tabular}{|c|c|c|c|c|c|c|c|c|c|c|c|c|}
\hline Fluid & Cell Size & Steps & Step & $\mathbf{k}\left(\frac{W}{m^{2} C}\right)$ & $\mathbf{h}\left(\frac{W}{m^{2} C}\right)$ & $q($ Watts $)$ & $\mathbf{T 1}(\mathrm{C})$ & S1(C) & $\mathrm{T} 2(\mathrm{C})$ & S2(C) & Time(s) & r2/4at \\
\hline $\mathrm{CuO}$ Nanofluid & $1 / 4 "$ & 7 & 1 & 0.03 & 165.13 & 0.03556 & 23.87 & 0.05 & 23.50 & 0.00 & 5180 & $1.76 \mathrm{E}-02$ \\
\hline $\mathrm{CuO}$ Nanofluid & $1 / 4^{\prime \prime}$ & 7 & 1 & 0.04 & 193.97 & 0.03500 & 23.81 & 0.04 & 23.50 & 0.00 & 6000 & $1.14 \mathrm{E}-02$ \\
\hline $\mathrm{CuO}$ Nanofluid & $1 / 4 "$ & 7 & 2 & 0.03 & 229.25 & 0.16080 & 25.71 & 0.09 & 24.51 & 0.03 & 3260 & $2.13 \mathrm{E}-02$ \\
\hline $\mathrm{CuO}$ Nanofluid & $1 / 4 "$ & 7 & 2 & 0.05 & 234.10 & 0.16032 & 25.87 & 0.07 & 24.70 & 0.00 & 6760 & $7.59 \mathrm{E}-03$ \\
\hline $\mathrm{CuO}$ Nanofluid & $1 / 4 "$ & 7 & 3 & 0.04 & 253.02 & 0.39026 & 28.70 & 0.13 & 26.06 & 0.07 & 3150 & $1.94 \mathrm{E}-02$ \\
\hline $\mathrm{CuO}$ Nanofluid & $1 / 4 "$ & 7 & 3 & 0.05 & 268.02 & 0.39000 & 28.74 & 0.17 & 26.25 & 0.09 & 4030 & $1.26 \mathrm{E}-02$ \\
\hline $\mathrm{CuO}$ Nanofluid & $1 / 4^{\prime \prime}$ & 7 & 4 & 0.05 & 259.30 & 0.70000 & 33.00 & 0.11 & 28.38 & 0.05 & 4280 & $1.23 \mathrm{E}-02$ \\
\hline $\mathrm{CuO}$ Nanofluid & $1 / 4^{\prime \prime}$ & 7 & 4 & 0.05 & 275.74 & 0.72000 & 33.03 & 0.10 & 28.57 & 0.05 & 3760 & $1.33 \mathrm{E}-02$ \\
\hline $\mathrm{CuO}$ Nanofluid & $1 / 4 "$ & 7 & 5 & 0.05 & 268.91 & 1.09868 & 37.89 & 0.18 & 30.90 & 0.07 & 4400 & $1.13 \mathrm{E}-02$ \\
\hline $\mathrm{CuO}$ Nanofluid & $1 / 4 "$ & 7 & 5 & 0.05 & 284.46 & 1.15368 & 38.22 & 0.31 & 31.28 & 0.15 & 3930 & $1.20 \mathrm{E}-02$ \\
\hline $\mathrm{CuO}$ Nanofluid & $1 / 4 "$ & 7 & 6 & 0.05 & 284.39 & 1.62216 & 43.93 & 0.27 & 34.17 & 0.11 & 3180 & $1.63 \mathrm{E}-02$ \\
\hline $\mathrm{CuO}$ Nanofluid & $1 / 4^{\prime \prime}$ & 7 & 6 & 0.05 & 292.87 & 1.65440 & 44.03 & 0.24 & 34.37 & 0.08 & 4180 & $1.06 \mathrm{E}-02$ \\
\hline $\mathrm{CuO}$ Nanofluid & $1 / 4 "$ & 7 & 7 & 0.05 & 297.23 & 2.07583 & 49.02 & 0.26 & 37.08 & 0.10 & 3560 & $1.31 \mathrm{E}-02$ \\
\hline $\mathrm{CuO}$ Nanofluid & $1 / 4 "$ & 7 & 7 & 0.09 & 303.53 & 2.14389 & 50.74 & 0.44 & 38.66 & 0.19 & 22990 & $1.21 \mathrm{E}-03$ \\
\hline $\mathrm{CuO}$ Nanofluid & $1 "$ & 7 & 1 & 0.01 & 163.10 & 0.05060 & 23.73 & 0.05 & 23.20 & 0.00 & 5190 & $1.54 \mathrm{E}+00$ \\
\hline $\mathrm{CuO}$ Nanofluid & $1 "$ & 7 & 2 & 0.01 & 195.84 & 0.19076 & 25.47 & 0.07 & 23.80 & 0.00 & 4550 & $1.50 \mathrm{E}+00$ \\
\hline $\mathrm{CuO}$ Nanofluid & $1 "$ & 7 & 3 & 0.01 & 199.81 & 0.42000 & 28.29 & 0.11 & 24.70 & 0.01 & 4850 & $1.44 \mathrm{E}+00$ \\
\hline $\mathrm{CuO}$ Nanofluid & $1 "$ & 7 & 4 & 0.01 & 201.90 & 0.76076 & 32.24 & 0.16 & 25.80 & 0.02 & 10870 & $1.02 \mathrm{E}+00$ \\
\hline $\mathrm{CuO}$ Nanofluid & $1 "$ & 7 & 5 & 0.01 & 197.75 & 1.17547 & 37.17 & 0.18 & 27.00 & 0.00 & 4680 & $1.48 \mathrm{E}+00$ \\
\hline $\mathrm{CuO}$ Nanofluid & $1 "$ & 7 & 6 & 0.01 & 204.85 & 1.67944 & 42.53 & 0.33 & 28.51 & 0.02 & 4400 & $1.50 \mathrm{E}+00$ \\
\hline $\mathrm{CuO}$ Nanofluid & $1 "$ & 7 & 7 & 0.01 & 210.50 & 2.11869 & 47.02 & 0.35 & 29.81 & 0.03 & 4970 & $1.39 \mathrm{E}+00$ \\
\hline $\mathrm{C}-\mathrm{Cu}$ Nanofluid & $1 / 4^{\prime \prime}$ & 1 & 1 & 0.00 & 306.13 & 2.10986 & 49.34 & 0.30 & 37.56 & 0.05 & 9700 & 4.43E-04 \\
\hline $\mathrm{C}-\mathrm{Cu}$ Nanofluid & $1 / 4 "$ & 1 & 1 & 0.08 & 328.39 & 2.19494 & 48.77 & 0.28 & 37.34 & 0.09 & 10503 & $8.13 \mathrm{E}-02$ \\
\hline $\mathrm{C}-\mathrm{Cu}$ Nanofluid & $1 "$ & 1 & 1 & 0.05 & 175.16 & 2.18595 & 52.09 & 2.10 & 30.74 & 1.74 & 5767 & $2.05 \mathrm{E}-01$ \\
\hline $\mathrm{C}-\mathrm{Cu}$ Nanofluid & $1 "$ & 1 & 1 & 0.04 & 206.95 & 2.18595 & 48.56 & 0.36 & 30.49 & 0.03 & 7600 & $2.07 \mathrm{E}-01$ \\
\hline $\mathrm{C}-\mathrm{Cu}$ Nanofluid & $1 "$ & 1 & 1 & 0.03 & 193.95 & 2.15296 & 50.60 & 0.36 & 30.12 & 0.04 & 8750 & $3.28 \mathrm{E}-02$ \\
\hline
\end{tabular}


TABLE VI

RESULTS FROM THE REPEATED $1 / 4$ " HEAT TRANSFER CELL OF THE FIRST DESIGN WITH FRESH MINERAL OIL

\begin{tabular}{|c|c|c|c|c|c|c|c|c|c|c|}
\hline Fluid & Step & $\mathbf{k}\left(\frac{W}{m^{2} C}\right)$ & $\mathbf{h}\left(\frac{W}{m^{2} C}\right)$ & $\mathbf{Q}($ Watts) & $\mathbf{T 1}(\mathbf{C})$ & $\mathbf{S 1 ( C )}$ & $\mathbf{T 2}(\mathbf{C})$ & $\mathbf{S 2}(\mathbf{C})$ & Time(s) & $\mathbf{r 2 / 4 a t}$ \\
\hline Mineral Oil & 1 & 0.17 & 709.31 & 0.04 & 21.63 & 0.05 & 21.71 & 0.04 & 4220 & $3.35 \mathrm{E}-03$ \\
\hline Mineral Oil & 2 & 0.14 & 576.10 & 0.16 & 22.86 & 0.05 & 23.34 & 0.08 & 4980 & $3.53 \mathrm{E}-03$ \\
\hline Mineral Oil & 3 & 0.11 & 480.82 & 0.39 & 25.00 & 0.03 & 26.39 & 0.11 & 5530 & $3.88 \mathrm{E}-03$ \\
\hline Mineral Oil & 4 & 0.10 & 473.49 & 0.70 & 27.62 & 0.07 & 30.15 & 0.28 & 4530 & $5.09 \mathrm{E}-03$ \\
\hline Mineral Oil & 5 & 0.13 & 538.07 & 1.13 & 30.51 & 0.05 & 34.09 & 0.16 & 5190 & $3.65 \mathrm{E}-03$ \\
\hline Mineral Oil & 6 & 0.16 & 622.75 & 1.62 & 34.13 & 0.13 & 38.59 & 0.25 & 5900 & $2.60 \mathrm{E}-03$ \\
\hline Mineral Oil & 7 & 0.15 & 642.62 & 2.11 & 37.11 & 0.14 & 42.72 & 0.61 & 4900 & $3.15 \mathrm{E}-03$ \\
\hline
\end{tabular}




\section{LIST OF REFERENCES}

Alvarado, S., E. Marín, A. G. Juárez, A. Calderón and R. Ivanov (2012). "A hotwire method based thermal conductivity measurement apparatus for teaching purposes." European Journal of Physics 33(4): 897.

Choi, C., H. S. Yoo and J. M. Oh (2008). "Preparation and heat transfer properties of nanoparticle-in-transformer oil dispersions as advanced energy-efficient coolants." Current Applied Physics 8(6): 710-712.

Du, Y., Y. Lv, C. Li, Y. Zhong, M. Chen, S. Zhang, Y. Zhou and Z. Chen (2012). "Effect of water adsorption at nanoparticle-oil interface on charge transport in high humidity transformer oil-based nanofluid." Colloids and Surfaces A: Physicochemical and Engineering Aspects 415(0): 153-158.

Eastman, J. A., S. U. S. Choi, S. Li, W. Yu and L. J. Thompson (2001). "Anomalously increased effective thermal conductivities of ethylene glycol-based nanofluids containing copper nanoparticles." Applied Physics Letters 78(6): 718.

Elias, M. M., M. Miqdad, I. M. Mahbubul, R. Saidur, M. Kamalisarvestani, M. R. Sohel, A. Hepbasli, N. A. Rahim and M. A. Amalina (2013). "Effect of nanoparticle shape 
on the heat transfer and thermodynamic performance of a shell and tube heat exchanger." International Communications in Heat and Mass Transfer 44(0): 93-99.

Gibbs, K. (2013). "Heat Capacity and Specific Heat Capacity." Retrieved 12-8, 2013, from http://www.schoolphysics.co.uk/age1619/Thermal\%20physics/Heat\%20energy/text/Heat_energy/index.html.

Green, D. and R. Perry (2008). Perry's Chemical Engineers' Handbook, McGrawHill.

Harlow, J. H. (2004). Electric Power Transformer Engineering, CRC Press LLC.

Incropera, F., D. Dewitt, T. Bergman and A. Lavine (2007). Fundamentals of Heat and Mass Transfer, John Wiley \& Sons.

Keblinski, P., S. R. Phillpot, S. U. S. Choi and J. A. Eastman (2002). "Mechanisms of heat flow in suspensions of nano-sized particles (nanofluids)." International Journal of Heat and Mass Transfer 45(4): 855-863.

Keblinski, P., R. Prasher and J. Eapen (2008). "Thermal conductance of nanofluids: is the controversy over?" Journal of Nanoparticle Research 10(7): 1089-1097.

Kwak, K. and C. Kim (2005). "Viscosity and thermal conductivity of copper oxide nanofluid dispersed in ethylene glycol." Korea-Australia Rheology Journal 17(2): 35-40.

Lee, J.-C., W.-H. Lee, S.-H. Lee and S. Lee (2012). "Positive and negative effects of dielectric breakdown in transformer oil based magnetic fluids." Materials Research Bulletin 47(10): 2984-2987.

Leitner, J., P. Chuchvalec, D. Sedmidubský, A. Strejc and P. Abrman (2002). "Estimation of heat capacities of solid mixed oxides." Thermochimica Acta 395(1-2): 2746. 
Ltd., C.-T. T. (2014). "The Methods." Retrieved 6/24, 2014, from http://www.ctherm.com/technology/understanding the_methods/.

Murshed, S. M. S., K. C. Leong and C. Yang (2008). "Investigations of thermal conductivity and viscosity of nanofluids." International Journal of Thermal Sciences 47(5): $560-568$.

Nagasaka, Y. and A. Nagashima (1981). "Absolute measurement of the thermal conductivity of electrically conducting liquids by the transient hot-wire method." Journal of Physics E: Scientific Instruments 14(12): 1435.

P.E., W. H. B. (2003). "Analysis of Transformer Failures." 13.

Rucker, M. (2011). ANALYSIS OF PARAMETERS IMPACTING THE HEAT TRANSFER COEFFICIENT IN OIL-BASED NANOFLUIDS. Master's of Engineering, University of Louisville.

Srinivasan, C. and R. Saraswathi (2012). "Nano-oil with high thermal conductivity and excellent electrical insulation properties for transformers." $\underline{\text { Current Science }}$ (00113891) 102(10): 1361-1363.

Taha-Tijerina, J., T. N. Narayanan, G. Gao, M. Rohde, D. A. Tsentalovich, M. Pasquali and P. M. Ajayan (2012). "Electrically Insulating Thermal Nano-Oils Using 2D Fillers." ACS Nano 6(2): 1214-1220.

Tomčo, L., K. Marton, F. Herchl, P. Kopčanský, I. Potočová, M. Koneracká and M. Timko (2006). "The DC and AC insulating properties of magnetic fluids based on transformer oil." physica status solidi (c) 3(1): 195-198.

Xuan, Y. and Q. Li (2000). "Heat transfer enhancement of nanofluids." International Journal of Heat and Fluid Flow 21(1): 58-64. 
Yu, W. and H. Xie (2012). "A Review on Nanofluids: Preparation, Stability Mechanisms, and Applications." Journal of Nanomaterials 2012.

Yulong Ding, H. C., Liang Wang, Chane-Yuan Yang, and Yurong He1, Wei Yang1, Wai Peng Lee1, Lingling Zhang1 and Ran Huo1 (2007). "Heat Transfer Intensification Using Nanofluids." 16.

Zhou, L.-P., B.-X. Wang, X.-F. Peng, X.-Z. Du and Y.-P. Yang (2010). "On the Specific Heat Capacity of CuO Nanofluid." Advances in Mechanical Engineering 2010. 


\section{CURRICULUM VITAE}

NAME:

Eli Wilborn

ADDRESS: $\quad$ Department of Chemical Engineering

University of Louisville

Louisville, KY 40292

EDUCATION: $\quad$ B.S. Chemical Engineering

University of Louisville

2009-2013

WORKING

EXPERIENCE: $\quad$ Engineering Co-op

Ashland Specialty Ingredients (formerly International

Specialty Products)

2011-2012

Calverty City, KY 